\title{
The cystic fibrosis lung microenvironment alters antibiotic activity: causes and effects
}

\author{
Sara Van den Bossche $\mathbb{( \mathbb { l }}^{1}$, Emma De Broe ${ }^{1}$, Tom Coenye $\mathbb{1}^{1}$, Eva Van Braeckel $\mathbb{\mathbb { D }}^{2,3}$ and Aurélie Crabbé ${ }^{1}$
}

${ }^{1}$ Laboratory of Pharmaceutical Microbiology, Ghent University, Ghent, Belgium. ${ }^{2}$ Dept of Respiratory Medicine, Cystic Fibrosis Reference Centre, Ghent University Hospital, Ghent, Belgium. ${ }^{3}$ Dept of Internal Medicine and Paediatrics, Ghent University, Ghent, Belgium.

Corresponding author: Aurélie Crabbé (aurelie.crabbe@ugent.be)

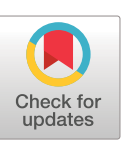

Copyright @The authors 2021

This version is distributed under the terms of the Creative Commons Attribution NonCommercial Licence 4.0. For commercial reproduction rights and permissions contact permissions@ersnet.org

Received: 8 March 2021 Accepted: 23 April 2021

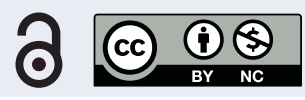

Shareable abstract (@ERSpublications)

Bacterial and host mediators in the CF lung milieu influence antibiotic susceptibility of Pseudomonas aeruginosa, and vary between patients. This could explain why current antibiotic susceptibility tests poorly predict activity in patients. https://bit.ly/3vtYsRU

Cite this article as: Van den Bossche S, De Broe E, Coenye T, et al. The cystic fibrosis lung microenvironment alters antibiotic activity: causes and effects. Eur Respir Rev 2021; 30: 210055 [DOI: 10.1183/16000617.0055-2021].

\section{Abstract}

Chronic airway colonisation by Pseudomonas aeruginosa, a hallmark of cystic fibrosis (CF) lung disease, is associated with increased morbidity and mortality and despite aggressive antibiotic treatment, $P$. aeruginosa is able to persist in CF airways. In vitro antibiotic susceptibility assays are poor predictors of antibiotic efficacy to treat respiratory tract infections in the CF patient population and the selection of the antibiotic(s) is often made on an empirical base. In the current review, we discuss the factors that are responsible for the discrepancies between antibiotic activity in vitro and clinical efficacy in vivo. We describe how the CF lung microenvironment, shaped by host factors (such as iron, mucus, immune mediators and oxygen availability) and the microbiota, influences antibiotic activity and varies widely between patients. A better understanding of the CF microenvironment and population diversity may thus help improve in vitro antibiotic susceptibility testing and clinical decision making, in turn increasing the success rate of antibiotic treatment.

\section{Introduction}

Cystic fibrosis (CF) is the most common life-threatening inheritable disease in the Caucasian population, as one in 3000-4000 newborns is affected [1]. Due to mutations in the cystic fibrosis transmembrane conductance regulator gene (CFTR), which results in mucus dehydration and stasis, the airways of patients with CF are particularly susceptible to chronic bacterial infections. These infections are followed by an aggressive inflammatory response, resulting in progressive airway tissue damage, lung function decline and premature death [1].

While a decreasing prevalence of the opportunistic pathogen Pseudomonas aeruginosa has been observed in patients with CF in recent years [2], it is still one of the most important causes of morbidity and mortality in the CF population [3]. The use of CFTR modulator drugs, which restore at least in part the underlying genetic defect, have shown promise in delaying the initial acquisition of $P$. aeruginosa, yet the long-term effects on chronic colonisation of this pathogen remain to be determined [4]. Annual reports of various national CF registries show that the percentage of the CF population with a positive culture for $P$. aeruginosa increases with older age, with a stabilisation at around $50-70 \%$ after the age of 20-25 years [2, 3]. The mean age of the first $P$. aeruginosa acquisition ranges between 6.5 and 7.1 years [5]. Although eradication of these early infections is feasible with antibiotic therapy, intermittent and chronic infections emerge more often as patients grow older [3]. The switch from intermittent to chronic infections is mediated by the ability of $P$. aeruginosa to form biofilms, which are communities of aggregated bacteria present in a self- or host-produced matrix that provide shelter from the immune system and antimicrobials $[6,7]$. Antibiotic therapy is used both for eradication of the initial infection and for control of chronic 
infections, but also in periods of pulmonary exacerbations. For early eradication therapy, regimens differ between CF centres, with no clear consensus on the most effective one [8]. A study comparing the combination of oral ciprofloxacin and inhaled tobramycin with the combination of oral ciprofloxacin and inhaled colistin showed both treatments were equally effective (successful eradication in $66 \%$ of the patients) [9]. Chronic P. aeruginosa infections are typically managed (i.e. slowing down disease progression, as eradication is often no longer possible) by inhalation therapy with nebulised tobramycin, colistin, aztreonam or levofloxacin or with dry powder inhalators of ciprofloxacin or tobramycin [10-13]. The treatment of pulmonary exacerbations, however, is primarily based on the administration of oral (ciprofloxacin) or intravenous antibiotics ( $\beta$-lactam antibiotics combined with aminoglycosides or colistin) with within- and between-centre differences in antibiotic choice $[14,15]$. Although the decision on which antibiotic to administer conventionally depends on the results of standardised antibiotic susceptibility testing (AST), a poor correlation exists between the outcome of AST and the effectiveness of antibiotics to control chronic infections and treat pulmonary exacerbations in vivo [16, 17]. Therefore, antibiotic choice is mostly empirically based in these cases and driven by the experience of physician and patient, including previous toxicity or intolerance, rather than on in vitro test results [18]. Other factors determining the antibiotic choice are practical reasons in the case of outpatient parenteral antibiotic therapy, or previous or current colonisation with other pathogens such as Staphylococcus aureus [19]. This discordance between in vitro activity and in vivo efficacy has, to our knowledge, not yet been described for early eradication therapy. Nevertheless, the success of antibiotic treatment for early eradication varies between patients, which further challenges the current one-treatment-fits-all approach [9, 18]. The reasons for this lack of predictability of treatment success, and the discrepancy between in vitro activity and in vivo antibiotic efficacy, are poorly understood. A few reports have linked specific phenotypic traits of $P$. aeruginosa isolates, such as mucoidy or diminished motility, to unsuccessful eradication (reviewed in JACKSON and WATERs [20]), while others did not find any association between phenotype and persistence. Therefore, there is an increasing interest in understanding the role of the CF lung microenvironment, which comprises host factors (e.g. nutrients, metabolites, immune cells and their mediators) and bacterial factors (lung microbiota) in the bacterial response to antibiotics.

Here we provide an overview of microenvironmental factors in the CF lung that are encountered during the infection process of $P$. aeruginosa and have been documented to influence the activity of antibiotics in vitro. These microenvironmental factors influence the susceptibility of $P$. aeruginosa to antibiotics directly, and on top of that, intra- and interpatient variability in the microenvironment can lead to diversification in the bacterial population, affecting antibiotic susceptibility. In the first part of the present review, we will provide an overview of host and microbial factors influencing antibiotic activity towards P. aeruginosa, both in early and chronic infections. In the second part, we highlight intra- and interpatient variability in the microenvironment, and its downstream effect on $P$. aeruginosa susceptibility. These collective insights may offer explanations for the difficulties in eradicating $P$. aeruginosa chronic infections and the high interpatient variability in therapeutic success, and identify knowledge gaps that may guide us towards optimisation of antibiotic use in patients with CF.

Host factors in the lung microenvironment influencing antibiotic activity Microenvironmental factors can influence the activity of antibiotics against $P$. aeruginosa through different mechanisms: 1) by altering bacterial physiology in a way that impacts tolerance; 2) by interfering with biofilm formation; and/or 3) by influencing mucus composition (figure 1). Host microenvironmental factors that influence antibiotic activity and their mode of action are discussed below and summarised in table 1.

\section{High iron availability}

CF airway secretions contain high concentrations of iron (on average $242 \mathrm{ng} \cdot \mathrm{mg}^{-1}$ in CF sputum while it is nondetectable in non-CF sputum) [64]. Firstly, airway epithelial cells, homozygous for the most common CFTR mutation (F508del), release more iron than healthy epithelial cells in vitro due to a lower expression of haemeoxygenase-1 resulting in higher intracellular iron levels [65]. Secondly, inflammatory and epithelial cell death is induced by bacterial pathogens and an aggressive immune response, which releases intracellular ferritin [66]. Ferritin, an innate defence molecule able to sequester ferric ions $\left(\mathrm{Fe}^{3+}\right)$, can readily release these ions in the presence of siderophores produced by $P$. aeruginosa [66]. $P$. aeruginosa produces two types of siderophores, pyoverdine and pyochelin; both contribute to the pathogen's virulence by depriving host cells of iron, providing iron for bacterial growth, stimulating the production of other virulence factors and promoting biofilm formation [67]. Interestingly, the production of siderophores is typically diminished in isolates that are adapted to the CF airways [68]. In most biological environments, ferric iron is the most common ionic state of iron. In the CF lung, however, the high levels of neutrophilic superoxides, low oxygen levels and acidic $\mathrm{pH}$ are believed to contribute to the high 

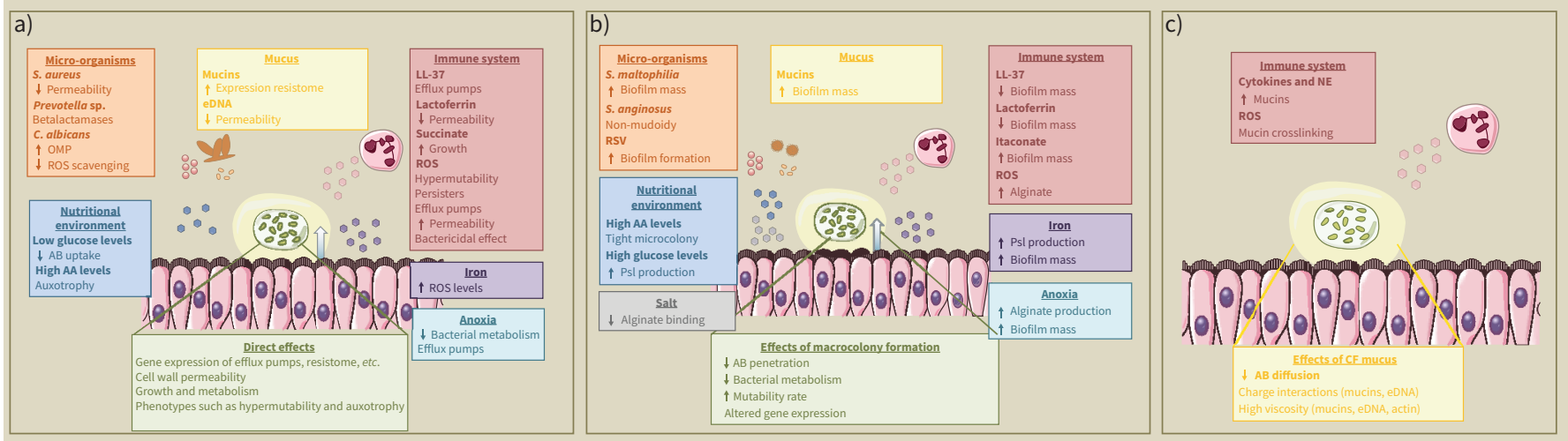

FIGURE 1 Host and microbial factors that are part of the cystic fibrosis (CF) lung microenvironment to which Pseudomonas aeruginosa is exposed during the infection process, and their direct effects on a) bacterial physiology, b) both bacterial physiology and antibiotic availability through interference with biofilm formation, and c) antibiotic availability through influence on mucus composition. AA: amino acids; AB: antibiotic; eDNA: extracellular DNA; NE: neutrophil elastase; OMP: outer membrane protein; ROS: reactive oxygen species; RSV: respiratory syncytial virus.

percentage (56\%) of ferrous ions $\left(\mathrm{Fe}^{2+}\right)$ being present [69]. P. aeruginosa is able to take up both ferric and ferrous iron [69]. High iron levels can influence the activity of antibiotics in multiple ways. Firstly, higher iron levels influence $P$. aeruginosa biofilm formation and thus antibiotic activity. Indeed, airway epithelial cells, homozygous for F508del, increase biofilm formation in comparison to airway epithelial cells with functioning CFTR, leading to higher tolerance to tobramycin [21]. Furthermore, iron availability and the transport of ferric iron by the siderophore pyoverdine is necessary for biofilm formation, with higher iron concentrations required in anoxic conditions [70]. High iron levels were also reported to modify biofilm structure (i.e. biofilm thickness and biomass), whereas iron sequestration, a possible treatment strategy, resulted in a lower biomass of the lab strain P. aeruginosa PAO1 and some clinical isolates [71]. This biofilm promoting effect of high iron levels was found to be the result of Psl production, an important exopolysaccharide [22]. Psl decreases antibiotic activity towards $P$. aeruginosa not only in biofilms, but also in planktonic cells by electrostatic interaction between Psl and antibiotics (tobramycin, colistin, polymyxin B and ciprofloxacin) [23]. The possible therapeutic use of iron chelators is, however, challenged by the finding that iron limitation can induce production of the expolysaccharide alginate and result in mucoidy [72], which in turn impacts antibiotic penetration [73].

Secondly, iron can influence antibiotic activity through its role in the production of reactive oxygen species (ROS), mediated by the Fenton reaction. High levels of intracellular ferrous iron $\left(\mathrm{Fe}^{2+}\right)$ shift the balance of the Fenton reaction in favour of ROS production. Downstream effects thereof on antibiotic activity are discussed in the section "Mediators of the immune response".

\section{Viscous mucus}

Mucus in CF airways is characterised by a higher concentration of mucins, such as MUC5AC and MUC5B, due to volume depletion caused by the CFTR defect and increased mucin production as a consequence of bacterial infection and inflammation [74]. CF lung mucus also contains large amounts of extracellular DNA (eDNA, 3-14 $\mathrm{mg} \cdot \mathrm{mL}^{-1}$ ) and actin $[75,76]$. Variable sources of eDNA in CF sputum have been described, including living bacterial cells that actively secrete DNA [77], DNA released from bacterial membrane vesicles [78], lysed bacterial cells [79] and neutrophil NETosis and/or necrosis. The latter can be induced by $P$. aeruginosa virulence factors (e.g. rhamnolipids) or by the combination of bacterial ingestion and airway surface liquid acidification [80, 81]. The high levels of actin in CF sputum are also a consequence of excessive neutrophilic inflammation, since neutrophils induce actin polymerisation in response to chemotactic stimulation [82]. In turn, actin filaments improve eDNA fibre formation in CF mucus [83].

The specific composition of CF mucus (high mucin content, eDNA and actin) leads to a high viscosity, which lowers the diffusion rate and impedes the efficient penetration of antibiotics [27, 31, 34]. In addition to increasing viscosity, mucins and eDNA - which have a net negative charge [84] - interact with the positively charged aminoglycosides, colistin and polymyxin B [25, 30,34]. Mucins can also interact with antibiotics (aztreonam, ceftazidime and levofloxacin) through hydrophobic interactions [26]. Additionally, 
TABLE 1 A summary of all host factors influencing antibiotic activity towards Pseudomonas aeruginosa

\begin{tabular}{|c|c|c|c|c|}
\hline Host factor & Antibiotic(s) $)^{\#}$ & $\begin{array}{l}\text { Antibiotic } \\
\text { activity }\end{array}$ & Mechanism & References \\
\hline \multirow[t]{2}{*}{ High iron availability } & Tobramycin & $\downarrow$ & Increased biofilm formation & {$[21]$} \\
\hline & $\begin{array}{l}\text { Tobramycin, colistin, polymyxin B, } \\
\text { ciprofloxacin }\end{array}$ & $\downarrow$ & $\begin{array}{l}\text { Increased Psl production, changed biofilm } \\
\text { structure and enhanced antibiotic } \\
\text { tolerance }\end{array}$ & {$[22,23]$} \\
\hline \multicolumn{5}{|l|}{ Mucus } \\
\hline \multirow[t]{4}{*}{ Mucins } & $\begin{array}{l}\text { Tobramycin, colistin, polymyxin B, } \\
\text { levofloxacin, aztreonam, ceftazidim }\end{array}$ & $\downarrow$ & $\begin{array}{l}\text { Antibiotic binding through charge and/or } \\
\text { hydrophobic interactions }\end{array}$ & [24-26] \\
\hline & Gentamicin, $\beta$-lactam antibiotics & $\downarrow$ & $\begin{array}{l}\text { Higher viscosity } \\
\text { Lower diffusion rate }\end{array}$ & {$[27]$} \\
\hline & $\begin{array}{l}\text { Aminoglycosides, colistin, polymyxin B, } \\
\text { norfloxacin, ciprofloxacin, } \beta \text {-lactam } \\
\text { antibiotics }\end{array}$ & $\downarrow$ & Induction of expression of resistance genes & [28] \\
\hline & Tobramycin & $\downarrow$ & Increased biofilm formation & [29] \\
\hline \multirow[t]{2}{*}{ Extracellular DNA } & Tobramycin & $\downarrow$ & $\begin{array}{l}\text { Charge interaction } \\
\text { Higher viscosity, leading to lower antibiotic } \\
\text { diffusion }\end{array}$ & {$[30,31]$} \\
\hline & Aminoglycosides, colistin, polymyxin B & $\downarrow$ & $\begin{array}{l}\mathrm{Mg}^{2+} \text { sequestration and acidification, leading } \\
\text { to LPS modification }\end{array}$ & {$[32,33]$} \\
\hline Actin & Tobramycin, colistin & $\downarrow$ & $\begin{array}{l}\text { Higher viscosity, leading to lower antibiotic } \\
\text { diffusion }\end{array}$ & [34] \\
\hline \multirow[t]{4}{*}{ Anoxia } & Aminoglycosides & $\downarrow$ & Low metabolism & [35-37] \\
\hline & $\beta$-lactam antibiotics & $\downarrow$ & Higher expression of efflux pumps & {$[38,39]$} \\
\hline & Tobramycin & $\downarrow$ & Increased alginate production & [40-43] \\
\hline & Colistin & $\uparrow$ & $\begin{array}{l}\text { Low metabolism leads to inactivation of } \\
\text { adaptive resistance mechanisms }\end{array}$ & {$[38,39]$} \\
\hline \multicolumn{5}{|c|}{ Nutritional environment } \\
\hline $\begin{array}{l}\text { Low glucose levels, } \\
\text { high amino acid } \\
\text { levels }\end{array}$ & Tobramycin, ciprofloxacin & $\downarrow$ & $\begin{array}{l}\text { Development of auxotrophy and } \\
\text { co-occurrent LasR mutations }\end{array}$ & {$[44-46]$} \\
\hline High glucose levels & Ofloxacin & $\downarrow$ & $\begin{array}{l}\text { Promotion of biofilm formation by inducing } \\
\text { Psl production }\end{array}$ & {$[47,48]$} \\
\hline \multicolumn{5}{|l|}{$\mathrm{NaCl}$ content and $\mathrm{pH}$} \\
\hline \multirow[t]{2}{*}{ High $\mathrm{NaCl}$ content } & Tobramycin, streptomycin & $\uparrow$ & Reduced alginate binding & {$[49,50]$} \\
\hline & Colistin, ciprofloxacin & $\uparrow$ & Synergism & {$[51,52]$} \\
\hline Acidic pH & Tobramycin, ceftazidim, ciprofloxacin & $\downarrow$ & Induction of biofilm formation & {$[53]$} \\
\hline \multicolumn{5}{|l|}{ Immune response } \\
\hline LL-37 & Gentamicin, ciprofloxacin & $\downarrow$ & Upregulation of multidrug efflux pumps & [54] \\
\hline Lactoferrin & Tobramycin & $\downarrow$ & $\begin{array}{l}\text { Depolarization of bacterial membrane, } \\
\text { leading to less antibiotic uptake }\end{array}$ & [55] \\
\hline $\begin{array}{l}\text { IL-1 } \beta, \text { IL-6, IL-17 } \\
\text { and neutrophil } \\
\text { elastase }\end{array}$ & Aspecific & $\downarrow$ & Induction of mucin production & [56] \\
\hline Itaconaat & Aspecific & $\downarrow$ & $\begin{array}{l}\text { Induction of biofilm formation through EPS } \\
\text { formation }\end{array}$ & [57] \\
\hline \multirow[t]{4}{*}{ ROS } & Aspecific & $\downarrow$ & Increased alginate production & {$[58]$} \\
\hline & & & $\begin{array}{l}\text { Higher oxidation level of mucins, leading to } \\
\text { less antibiotic diffusion }\end{array}$ & {$[59,60]$} \\
\hline & & & $\begin{array}{l}\text { Higher occurrence of hypermutators, which } \\
\text { is linked to higher occurrence of persisters }\end{array}$ & [61] \\
\hline & Aminoglycosides & $\downarrow$ & $\begin{array}{l}\text { Induction of efflux pump gene expression } \\
\text { Reduced membrane potential and } \\
\text { modification of LPS }\end{array}$ & [62] \\
\hline
\end{tabular}

LPS: lipopolysaccharide; EPS: exopolysaccharide; ROS: reactive oxygen species; \#: if the effects are described for more than two antibiotics of an antibiotic class, the class is mentioned; if a host factor has a speculative, indirect effect on antibiotic activity in general, the term "aspecific" is used; ": the definition of antibiotic activity differs between studies; in some studies activity is measured by minimal inhibitory concentration and in other studies by performing biofilm experiments, ranging from biofilms formed on plastic to biofilms in the presence of in vivo-like epithelial cell models. 
eDNA and mucins influence expression of genes involved in antibiotic resistance. Specifically, eDNA interferes with the PA3552-PA3559 cationic antimicrobial peptide (CAP) resistance operon, resulting in a lipopolysaccharide (LPS) modification and thus reduced cell wall permeability to aminoglycosides and polymyxins [32]. This effect is due to $\mathrm{Mg}^{2+}$ sequestration and acidification by eDNA [32, 33]. Similarly, Sun et. al [28] described that mucins influence the expression of multiple resistance genes leading to broad spectrum adaptive antibiotic resistance. This altered gene expression also results in enhanced surfing motility, a form of surface adaptation, in which mucins act as a surfactant allowing rapid surface motility of $P$. aeruginosa [28].

In addition, interactions of $P$. aeruginosa with mucins are reported to result in the formation of larger cellular macrocolonies with increased antibiotic tolerance compared with biofilms formed on uncoated surfaces or surfaces coated with DNA or actin [29].

\section{Hypoxia}

As a consequence of mucus stasis, $P$. aeruginosa is exposed to low oxygen levels in the CF airways. Indeed, the thick mucus layer impedes oxygen diffusion, leading to steep hypoxic gradients in thick, mucopurulent masses [40]. Additionally, higher oxygen consumption in CF epithelial cells and neutrophils, a side-effect of the higher sodium uptake due to CFTR malfunction, further contributes to hypoxia [85]. Moreover, $P$. aeruginosa penetrates in mucopurulent masses shortly after infection and consumes the remaining oxygen, leading to complete anoxia locally [40]. $P$. aeruginosa is able to grow in anaerobic conditions in the presence of an alternative terminal electron acceptor (e.g. nitrate) [35] or by arginine fermentation [86]. Nitrate is present in higher concentrations in CF sputum [35, 87], which is a consequence of the chemical reaction between the immune effectors nitric oxide and superoxide [87]. High levels of nitrate stimulate anaerobic respiration and thus enable bacterial metabolism in anoxia.

Reduced antimicrobial activity in anoxia has been reported for aminoglycosides (tobramycin, amikacin and gentamicin), aztreonam, ceftazidim and the combination of penicillins with a $\beta$-lactamase inhibitor (piperacilline-tazobactam and ticarcillin-clavulanic acid) [75, 89-92]. Anaerobic conditions have a minimal influence on the antibiotic activity of fluoroquinolones (ciprofloxacin and levofloxacin) [75, 89-92]. In contrast, an enhanced antimicrobial activity of tetracyclins and colistin in anoxia has been described [38, 90, 93]. Remarkably, although the general trend is clear, variability in outcomes between studies describing the influence of anoxia on antibiotic activity is observed. This variability can possibly be explained by the different strains of $P$. aeruginosa tested, with a profound difference between lab strains [38, 90, 91] (e.g. PAO1, PA14) and CF clinical isolates [89, 93, 94] and the use of different growth media (especially differences in arginine or $\mathrm{NO}_{3}{ }^{-}$levels could influence antibiotic activity in anoxia) [36].

The reduced activity of aminoglycoside antibiotics in anoxic conditions can be attributed to a lower bacterial metabolic rate. Many studies demonstrated an increased antibiotic susceptibility in anoxia upon addition of nitrate, nitrite or arginine, which stimulated metabolism [35-37]. The opposite has been reported for colistin, which has higher activity towards metabolically inactive cells [38, 39]. Indeed, metabolically inactive cells are incapable of activating energy-consuming adaptive resistance mechanisms, such as expression of efflux pumps and/or alteration of LPS (the target of colistin) [39]. Alternatively, inhibition of efflux pumps in anoxia led to a susceptibility profile similar to that in normoxia for ceftazidim, aztreonam, piperacilline-tazobactam and ticarcilline-clavulanic acid, indicating that efflux pumps (MexEF-OprN) are responsible for the low activity of these antibiotics in anoxic conditions [92].

Finally, anoxia leads to increased alginate production by $P$. aeruginosa, even in nonmucoid isolates, resulting in the formation of a more robust biofilm. As a consequence, this mechanism can contribute to higher tolerance towards antibiotics [40-43].

\section{Nutritional environment}

WETMORE et al. [95] reported an altered glucose metabolism in primary human airway epithelial cells from CF patients compared with non-CF cells, leading to lower levels of glucose in CF airways. Lower levels of carbon sources such as glucose may result in decreased bacterial production of electron donors (e.g. $\mathrm{NADH}$ ), a lower proton motive force (PMF), reduced levels of ROS (essential for the activity of some antibiotics) and thus higher tolerance to antibiotics which uptake depends on the PMF, such as aminoglycosides [7]. However, 29\% of the adult CF population has CF-related diabetes, and acute hyperglycaemia has been linked to high airway glucose concentrations [2, 47]. These high glucose levels have not only been associated with a higher bacterial load but also promote biofilm formation, through induction of Psl production [47, 48]. 
In addition, the increased neutrophilic protease activity in CF airways leads to a higher level of amino acids in CF airways (5-25 mM) compared with healthy airways [96]. P. aeruginosa adaptation to this specific nutritional environment (low glucose levels and high amino acid levels) often involves the development of auxotrophy and co-occurring LasR mutations, which are linked to fluoroquinolone and aminoglycoside tolerance [44-46]. Finally, the elevated levels of amino acids have been shown to be important to form tight biofilm-like macrocolonies, similar to those found in the CF airways [97].

\section{$\mathrm{NaCl}$ content and $\mathrm{pH}$}

Sputum $\mathrm{NaCl}$ concentrations in patients with $\mathrm{CF}$ are typically higher $\left(10.5 \mathrm{~g} \cdot \mathrm{L}^{-1}\right)$ in comparison with healthy controls $\left(7.4 \mathrm{~g} \cdot \mathrm{L}^{-1}\right)$ [88] as a consequence of CFTR malfunction. This high $\mathrm{NaCl}$ concentration can contribute to the vulnerability of CF airways to bacterial infections, by inhibiting the effect of endogenous antibacterial defences [98]. However, high $\mathrm{NaCl}$ concentrations can also lead to higher antibiotic activity by reducing alginate binding to antibiotics (aminoglycosides, tobramycin, streptomycin) $[49,50]$. Furthermore, a synergistic effect of $\mathrm{NaCl}$ on the antibiotic activity of colistin and ciprofloxacin was observed [51, 52].

Another secondary effect of CFTR malfunction is the acidification of the airway surface liquid (ASL) which has been reported both in vitro and in vivo [99, 100]. Recently, Lin et al. [53] have shown that low $\mathrm{pH}$ does not only lead to higher MIC (minimal inhibitory concentration) values, but also promotes biofilm formation and lowers the antibiofilm activity of tobramycin, ciprofloxacin and ceftazidime. Low $\mathrm{pH}$ also impacts the activity of antimicrobial peptides that are present in the ASL, such as $\beta$-defensins and LL-37, which exhibit synergistic activity with antibiotics under normal $\mathrm{pH}$ conditions [101].

\section{Mediators of the immune response}

As a result of chronic airway inflammation, CF lung mucus contains high levels of cytokines, proteases, oxidants and host antimicrobial compounds [102]. Although the excessive immune response aims at eradicating the infection, $P$. aeruginosa often persists, and several components of the immune response actually contribute to bacterial survival.

LL-37, an antimicrobial peptide, is produced by airway epithelial cells and neutrophils upon pathogen-recognition and thus is a part of the innate immune defence [103]. The levels of LL-37 in CF sputum correlate well with inflammation state [103]. LL-37 is capable of both inhibiting biofilm formation and eradicating preformed biofilms [104]. However, at physiological concentrations LL-37 leads to an upregulation of multidrug efflux pump genes (encoding MexCD-OprJ and MexGHI-OpmD) [54]. This leads to a decreased susceptibility of $P$. aeruginosa to ciprofloxacin and gentamicin.

The host-produced iron-chelator lactoferrin prevents $P$. aeruginosa biofilm formation in vitro [71, 105], but it seems unlikely this is relevant in vivo, as iron is abundantly present in CF sputum (see above). However, lactoferrin promotes antibiotic tolerance towards tobramycin, by depolarising the bacterial membrane and decreasing antibiotic uptake [55]. Recent results in a mouse model of chronic $P$. aeruginosa infection showed lactoferrin reduced excess iron levels, bacterial load and inflammation suggesting it could have potential as a new therapeutic [106]. However, the observed induction of antibiotic tolerance in vitro [55] suggests possible undesired side-effects.

Pro-inflammatory cytokines are soluble proteins, secreted by immune cells and epithelial cells after pathogen-recognition, with initiation and stimulation of the immune response as a consequence [102]. Besides being essential mediators of the immune response, some pro-inflammatory cytokines (i.e. IL-1 $\beta$, IL-6 and IL-17) stimulate the production of MUC5AC and MUC5B [56, 107], hereby further impeding mucociliary clearance [108] and promoting biofilm formation [29]. Similarly, neutrophil elastase, the major neutrophilic protease which is highly abundant in CF lungs [109], induces MUC5AC production [110].

Secretion of metabolites, such as succinate and itaconate, as a result of pathogen-induced immunometabolic changes in immune cells, has been reported to be altered in CF [111]. Excessive succinate secretion in CFTR mutant macrophages has been shown to be used by $P$. aeruginosa for growth, while secreted itaconate induces biofilm formation through the production of exopolysaccharides (EPS) [57]. In addition, succinate and other metabolites have been demonstrated to alter antibiotic activity against $P$. aeruginosa $[7,112,113]$.

Excessive neutrophilic inflammation, together with the previously discussed iron imbalance in CF airways, leads to high levels of ROS [114]. Additionally, ROS can not be inactivated efficiently as glutathion, a host antioxidant, is produced at lower levels in the CF airways [115]. The resulting high ROS levels have variable (indirect) effects on antibiotic activity. Firstly, $P$. aeruginosa produces more alginate in the 
presence of ROS [58], contributing to antibiotic tolerance. Secondly, high ROS levels lead to increased oxidation of mucins, promoting mucin crosslinking by which the rheological characteristics change, further impeding mucociliary clearance and antibiotic diffusion [59, 60]. Thirdly, the occurrence of "hypermutators" is associated with oxidative stress [61]. Hypermutators exhibit increased spontaneous mutation rates compared with wild type strains due to, among others, defects in DNA repair genes such as mutS and mutL [116]. Hypermutable strains can readily adapt, which is advantageous in stressful environments [61]. In addition, the hypermutator phenotype has been linked to the occurrence of increased levels of persister cells, which are dormant bacteria with low metabolic activity that are able to survive high doses of antibiotics [62], and comprise up to $1 \%$ of the total bacterial population in biofilms [117]. Another phenotype that has recently been linked to high antibiotic tolerance is the Phoenix phenotype in which metabolically active cells in the presence of high antibiotic concentrations become susceptible once subcultured [118]. Nevertheless, the influence of the microenvironment on the occurrence of this particular phenotype has not yet been explored. Fourthly, oxidative stress induces efflux pump gene expression, promoting aminoglycoside tolerance [62]. Excessive ROS production has also been reported to lead to a reduced membrane potential and modification of LPS, which potentiates tobramycin activity [63].

Microbial factors in the lung microenvironment influence antibiotic activity

CF lungs host a polymicrobial community, consisting of both bacteria and fungi. The fungal community is dominated by Candida albicans and Aspergillus fumigatus [119, 120]. The most common bacterial genera found in the CF airways, besides the conventional pathogens, are Streptococcus, Prevotella, Veillonella, Rothia and Actinomyces [121, 122]. The CF lung microbiome is highly variable, not only between patients, but also within patients [121, 122], and microbiome diversity differs with age, with a high diversity typically observed in young patients ( $<10$ years) and a lower diversity in older patients (i.e. lowest level of diversity is observed at an age of approximately 25 years, with minimal changes in diversity at older age) [122]. Lower microbial diversity is often correlated with a decline in lung function, and occurrence of chronic $P$. aeruginosa infections [122]. Interestingly, plenty of studies report interspecies interactions in which $P$. aeruginosa influences antibiotic activity towards other CF microbiome members (e.g. S. aureus, Streptococcus anginosus), while the susceptibility of $P$. aeruginosa is typically not affected [123]. Nevertheless, certain interspecies interactions have been reported to influence antibiotic activity against $P$. aeruginosa.

Most reported interspecies interactions influencing $P$. aeruginosa susceptibility to antibiotics involve CF pathogens. Mixed-species biofilms of $P$. aeruginosa with Stenotrophomonas maltophilia or Burkholderia cenocepacia resulted in a higher biomass of $P$. aeruginosa compared with a single-species biofilm [124, 125]. For co-cultures with $S$. maltophilia, this also led to lower activity of ciprofloxacin against $P$. aeruginosa [124]. In contrast, coexistence of mucoid $P$. aeruginosa and $S$. anginosus induces a conversion from the mucoid to the nonmucoid phenotype [126], a transformation possibly associated with higher susceptibility towards antibiotics. A recent evolution study of $P$. aeruginosa in the presence of $S$. aureus reported mutations in LPS biosynthesis pathways of $P$. aeruginosa, which in turn resulted in altered outer membrane properties, antibiotic penetration and thus reduced activity of $\beta$-lactam antibiotics [127, 128]. In most studies on interspecies interactions, co-cultures of two bacterial species are used, which is obviously an oversimplification compared with the complex microbial communities present in the CF airways. Per sputum sample, an average number of 6 to 13 species has been reported, based on culture [119, 129]. In a recent experimental evolution study, $P$. aeruginosa was co-cultured with five CF microbiome members - hereby more closely mimicking the polymicrobial CF environment [130]. In this study, the development of $P$. aeruginosa resistance to $\beta$-lactam antibiotics occurred during evolution irrespectively of the presence of the microbiome members.

In addition to the extensively studied CF pathogens, anaerobic species are gaining more interest in CF research as they are abundant in the CF lung microbiome and might play a role in the disease process [131]. With regard to their possible influence on antibiotic activity against $P$. aeruginosa, approximately $76 \%$ of Prevotella isolates, one of the most encountered genera in CF airways [122], produce $\beta$-lactamases, which protect against $\beta$-lactam antibiotics [132].

Inter-kingdom interactions also contribute to $P$. aeruginosa persistence in the CF airways. In mixed-species biofilms with $C$. albicans, for example, the expression of outer membrane proteins (OMP), that are intrinsic participants in antibiotic resistance, is induced while the expression of ROS scavenging enzymes is reduced; the latter promoting mutability [133]. In addition to bacteria and fungi, viruses such as rhinovirus and respiratory syncytial virus (RSV) often reside in the CF airways [134]. HendRICKs et al. [135] reported that RSV promotes the formation of $P$. aeruginosa biofilms on airway epithelial cells. This is 
explained by a dysregulation of iron homeostasis upon viral infection, resulting in release of extracellular vesicles by airway epithelial cells, providing high iron availability to $P$. aeruginosa $[135,136]$.

Intrapatient spatiotemporal variability in the microenvironment drives phenotypic diversity in P. aeruginosa

The described host and microbial factors that compose the CF lung microenvironment (figure 1) vary within the patient, both spatially and temporally. Different niches in CF lungs can be distinguished that vary in oxygen levels, $\mathrm{pH}$, antibiotic concentrations, nutrients, and inflammation state [137-140]. The steep oxygen gradient in CF mucus plugs, ranging from normoxia at the surface to almost complete anoxia in the centre [40], can separate the microbial community in niches depending on their oxygen preference (e.g. increased abundance of anaerobic species with depth) [138]. Additionally, the oxygen gradient influences the production of virulence factors (e.g. rhamnolipids) by P. aeruginosa, leading to a decreased production in deeper regions [138]. A 3-D microbiome analysis and metabolome cartography revealed that CF lung microbiome composition is niche-specific as well, and is influenced by spatial variations in metabolism and drug penetration [141]. For instance, an increased abundance of Achromobacter spp. was observed at the lower part of the lung, that rests on the diaphragm, where meropenem penetrated less. In addition, as lung disease progresses, long-term exposure to oxidative stress and proteases results in airway remodelling [142]. This affects mucociliary clearance and possibly impacts antibiotic penetration in the mucus layer [142]. Furthermore, higher salinity of CF sputum and higher levels of ferrous iron have been linked to disease progression, with no consensus on the direction of causality [69, 97]. The CF lung microbiome also varies with disease progression (i.e. microbiome diversity and abundance of anaerobes decrease with age), resulting in a significant within-patient variability [121].

P. aeruginosa adapts to the CF airways during chronic infections, through various genetic transformations [143-145]. The adaptation of $P$. aeruginosa not only results in different phenotypes of the same clone within one patient over time, but also in various phenotypes in one sputum sample [143, 146]. The latter is referred to as phenotypic diversity and is observed, for example, as small colony variants, mucoid variants and hypermutable variants (table 2). In vivo studies showed that diversification occurs soon after infection (i.e. in the first 10 years) [146]. After colonisation the infecting clone diverges into different sublineages, which subsequently evolve independently from each other. The independent evolution is attributed to localisation in different niches within the lungs, leading to complete spatial segregation between the different lineages $[146,147]$. Correspondingly, the 3-D microbiome and metabolome cartography study by GARG et al. [141] revealed that the distribution of $P$. aeruginosa biofilm-specific molecules was not similar to the distribution of $P$. aeruginosa itself, indicating spatial variation in biofilm formation. The molecular process leading to diversification is reported to be recombination [148], with genes regulating expression of efflux pumps, and the quorum-sensing regulator LasR being affected most frequently [145, 149].

This phenotypic diversity has a dual impact on antibiotic treatment. Firstly, mixed mucoid and nonmucoid communities of $P$. aeruginosa show a higher tolerance to LL-37 and oxidative stress, compared with single phenotype communities [156]. Secondly, phenotypic diversity will affect the reproducibility of standardised AST, in which only one isolate is typically considered [157]. Indeed, the mean number of susceptibility profiles per sputum sample (based on disc diffusion diameters) has been reported as six [158]. Hence, sampling one isolate will often not provide a representative picture of antibiotic resistance [158]. Alternatively, performing AST on different isolates, based on morphotype, was reported not to be a promising approach as

TABLE 2 Different phenotypes of Pseudomonas aeruginosa in the cystic fibrosis lung

\begin{tabular}{llc}
\hline Phenotype & Description & Reference \\
\hline Small colony variants & $\begin{array}{l}\text { Slow-growing } \\
\text { High antibiotic resistance }\end{array}$ & {$[150]$} \\
\hline $\begin{array}{l}\text { Mucoid variants } \\
\text { Auxotrophic variants }\end{array}$ & $\begin{array}{l}\text { Alginate overproduction } \\
\text { Dependent on specific amino acids for growth }\end{array}$ & {$[151]$} \\
\hline $\begin{array}{l}\text { Hypermutable variants } \\
\text { LasR deficient variants }\end{array}$ & $\begin{array}{l}\text { Very likely to develop multidrug resistance } \\
\text { Lower virulence: lower pyocyanin production, lower production of } \\
\text { LasA protease, less efficient biofilm initiation }\end{array}$ & {$[46]$} \\
\hline $\begin{array}{l}\text { Type III secretion system } \\
\text { deficient variants }\end{array}$ & $\begin{array}{l}\text { Deficient ExoU (effector protein) secretion: lower cytotoxicity and } \\
\text { lower virulence }\end{array}$ & {$[153]$} \\
\hline $\begin{array}{l}\text { Pyomelanine producing } \\
\text { variants }\end{array}$ & $\begin{array}{l}\text { Pyomelanine hyperproduction } \\
\text { Increased antibiotic resistance }\end{array}$ & {$[155]$} \\
\hline
\end{tabular}


different morphotypes do not necessarily have different antibiotic susceptibility profiles [158]. Pooling isolates, another alternative approach, performed in some centres, also leads to a nonrepresentative resistance profile, and low reproducibility remains an issue [157].

Altogether, the complex and variable CF airways create a phenotypically diverse bacterial population, rendering AST and antibiotic treatment in CF even more challenging.

Interpatient variability in the lung microenvironment could explain low benefits of "one-treatment-fits-all" approach

Each CF patient has a unique genetic background and evolution of the disease [12, 159] and high interpatient variability is observed in the lung microenvironment of patients with CF [160].

Firstly, interpatient variability has a genetic base, with over 2000 CFTR mutations described that can be classified in severe mutations (i.e. no functional CFTR protein) and mild mutations (i.e. reduced CFTR activity) [161]. However, within the same CFTR genotype, the manifestation of the disease can differ tremendously, which can (at least partially) be attributed to several modifier genes (e.g. inflammatory mediators, antioxidants, airway reactivity, etc.) [162]. In addition to the direct influence of CFTR functionality on parameters such as salinity [163], the composition of the oropharyngeal bacterial community is also related to the CFTR genotype [164], with possible downstream effects on antibiotic activity. Furthermore, the prescription of CFTR modulators fully depends on the CFTR genotype of patients, and CFTR modulators have been shown to interfere with antibiotic activity. More specifically, both Orkambi and Kalydeco enhance the activity of polymyxin B in vitro [165].

Second, CF is a multisystemic disease in which extrapulmonary manifestations, such as exocrine pancreatic insufficiency, CF-related diabetes or liver disease, are only partially explained through the patient's genotype [166]. The presence or absence of these disease manifestations and their metabolic consequences, will in turn influence the lung microenvironment [166]. Indeed, the rate of pulmonary function decline is clearly correlated to the degree of insulin insufficiency and hyperglycaemia [167].

Finally, the composition of the polymicrobial community in the CF lung differs tremendously between patients [121, 122]. Indeed, differences in community diversity, abundance of anaerobes and others have been described [168]. Similarly, most if not all of the above-described host microenvironmental factors (e.g. iron levels, eDNA concentration, nutritional composition and immune mediators) that influence antibiotic activity, vary between patients [21, 75, 76, 97] and can thus contribute to interpatient variability in response to antibiotics. A recent study by Raghuvanshi et al. [169] (2020) also demonstrated that the metabolome of individuals with CF was highly individualised, as $\beta$-diversity was greater across than within subjects.

Finally, drug bioavailability at the infection site is another important aspect to consider when evaluating (the lack of) antibiotic efficacy. Pharmacokinetics for certain antibiotics administered to patients with CF through inhalation, orally or intravenously differ from that in healthy controls $[170,171]$. Focusing on the CF lung microenvironment, the most impactful factor is most likely the altered mucus rheology, which causes diffusion-limiting interactions with antibiotics, as described earlier. In addition, salt content and the presence of plasma proteins in the mucus layer may further affect antibiotic bioavailability [170]. Indeed, a substantial proportion of patients with CF have haemoptysis [172], and plasma proteins (most commonly albumin, alpha1-acid glycoprotein (AGP) and lipoproteins) not only bind antibiotics [170], but also influence the susceptibility of P. aeruginosa in vitro [173].

Towards narrowing the gap between in vitro and in vivo antimicrobial susceptibility

There is a gap between the complex and patient-dependent nature of the CF lung microenvironment on the one hand, and the conditions in which standardised AST are carried. Indeed, standardised AST typically involves exposing a single $P$. aeruginosa isolate, in planktonic state, to antibiotics in bacterial growth media (Muller Hinton broth) and environmental conditions (aerobic) (EUCAST guidelines) that are by far not reflective of the in vivo microenvironment [174]. Most if not all of the described host and microbial factors are absent in conventional AST, and the biofilm phenotype and phenotypic diversity of $P$. aeruginosa observed in vivo, are not captured. Nevertheless, clinical studies focusing on biofilm susceptibility to guide antibiotic therapy did not show an improvement in $P$. aeruginosa density in sputum or lung function parameters compared with conventional AST [175]. Hence, mimicking the biofilm phenotype alone may not be sufficient to fill the gap between in vitro and in vivo antibiotic susceptibility. In this review, we highlighted individual host and microbial factors that negatively impact antibiotic activity, as well as factors that potentiate antibiotic activity. More research is necessary to reveal which 
microenvironmental factors are dominant contributors to the net susceptibility of $P$. aeruginosa to antibiotics in vivo, as potential inclusion of these factors in routine clinical microbiology protocols needs to be feasible from a cost, time and practical point of view. Systematically studying how the different microenvironmental factors influence antibiotic activity alone and when combined, could lead to identification of key contributors to the (lack of) treatment success, and help design more predictive model systems and next generation AST.

\section{Conclusion}

The overall complexity of the CF microenvironment and the microenvironmental diversity within and between patients is not considered in the current treatment approach, despite its strong influence on antibiotic activity in vitro. This could thus (at least in part) explain the discordance between in vitro activity and in vivo efficacy, the difficulties in eradicating $P$. aeruginosa from the CF airways and the high interpatient variability in therapeutic success. Nevertheless, a major gap that remains to be addressed, is to understand which microenvironmental factor(s) drive(s) P. aeruginosa susceptibility in vivo. Therefore, more in-depth and systematic research on the influence of the lung microenvironment and interpatient variability on antibiotic efficacy could bring much-needed insights to understand and tackle the high failure rate of antibiotic therapy in CF chronic airway infections.

Provenance: Submitted article, peer reviewed.

Acknowledgements: We apologise to those authors whose work could not be cited due to space limitations.

Conflict of interest: S. Van den Bossche has nothing to disclose. E. De Broe has nothing to disclose. T. Coenye has nothing to disclose. E. Van Braeckel has received grants from Vertex, Abbvie and Galapagos for which her institution (Ghent University, Ghent, Belgium) received the fees. A. Crabbé has nothing to disclose.

Support statement: This work was supported by the Fund Alphonse and Jean Forton (managed by the King Baudouin Foundation) and the Belgian Cystic Fibrosis Association (2017-J1810150-207750) and by the Research Foundation Flanders (FWO) (Odysseus grant to A. Crabbé (G.0.E53.14N) and a PhD fellowship to S. Van den Bossche (1S55719N)). Funding information for this article has been deposited with the Crossref Funder Registry.

\section{References}

1 De Boeck K. Cystic fibrosis in the year 2020: a disease with a new face. Acta Paediatr Int J Paediatr 2020; 109: 893-899.

2 Wanyama SS, Thomas M, Daneau G. Annual Report Belgian Cystic Fibrosis Registry (BCFR 2017). Brussels, Sciensano, 2017. https://www.sciensano.be/en/biblio/annual-report-belgian-cystic-fibrosis-registry-2017

3 Cystic Fibrosis Foundation. Cystic Fibrosis Foundation Patient Registry 2019 Annual Data Report. Bethseda, Cystic Fibrosis Foundation, 2019. https://www.cff.org/Research/Researcher-Resources/Patient-Registry/2019Patient-Registry-Annual-Data-Report.pdf

$4 \quad$ Kidd TJ. Pseudomonas aeruginosa infection after CFTR restoration: one step back, one step forward. Am J Respir Crit Care Med 2017; 195: 1550-1552.

5 Petrocheilou A, Papagrigoriou-Theodoridou M, Michos A, et al. Early life Pseudomonas aeruginosa infection in cystic fibrosis and lung disease progression. Glob Pediatr Health 2017; 4: 2333794X1773846.

6 Singh PK, Schaefer AL, Parsek MR, et al. Quorum-sensing signals indicate that cystic fibrosis lungs are infected with bacterial biofilms. Nature 2000; 407: 762-764.

7 Crabbé $A$, Jensen $P \varnothing$, Bjarnsholt $T$, et al. Antimicrobial tolerance and metabolic adaptations in microbial biofilms. Trends Microbiol 2019; 27: 850-863.

8 Mogayzel P, Naureckas E, Robinson K, et al. Eradication of initial Pseudomonas aeruginosa clinical care guidelines. Ann Am Thorac Soc 2019; 11: 1640-1650.

9 Taccetti G, Bianchini E, Cariani L, et al. Early antibiotic treatment for Pseudomonas aeruginosa eradication in patients with cystic fibrosis: a randomised multicentre study comparing two different protocols. Thorax 2012; 67: 853-859.

10 Ratjen F, Rietschel E, Kasel D, et al. Pharmacokinetics of inhaled colistin in patients with cystic fibrosis. J Antimicrob Chemother 2006; 57: 306-311.

11 Ramsey BW, Pepe MS, Quan JM, et al. Intermittent administration of inhaled tobramycin in patients with cystic fibrosis. N Engl J Med 1999; 340: 23-30.

12 Tiddens HAWM, De Boeck K, Clancy JP, et al. Open label study of inhaled aztreonam for Pseudomonas eradication in children with cystic fibrosis: the ALPINE study. J Cyst Fibros 2015; 14: 111-119.

13 McShane PJ, Weers JG, Tarara TE, et al. Ciprofloxacin dry powder for inhalation (ciprofloxacin DPI): technical design and features of an efficient drug-device combination. Pulm Pharmacol Ther 2018; 50: 72-79. 
Stanojevic S, Mcdonald A, Waters V, et al. Effect of pulmonary exacerbations treated with oral antibiotics on clinical outcomes in cystic fibrosis. Thorax 2017; 72: 327-332.

Cogen JD, Oron AP, Gibson RL, et al. Characterization of inpatient cystic fibrosis pulmonary exacerbations. Pediatrics 2017; 139: e20162642.

Hurley MN, Ariff AHA, Bertenshaw C, et al. Results of antibiotic susceptibility testing do not influence clinical outcome in children with cystic fibrosis. J Cyst Fibros 2012; 11: 288-292.

Somayaji R, Parkins MD, Shah A, et al. Antimicrobial susceptibility testing (AST) and associated clinical outcomes in individuals with cystic fibrosis: a systematic review. J Cyst Fibros 2019; 18: 236-243.

Döring G, Flume P, Heijerman $\mathrm{H}$, et al. Treatment of lung infection in patients with cystic fibrosis: current and future strategies. J Cyst Fibros 2012; 11: 461-479.

Cantón R, Cobos N, de Gracia J, et al. Antimicrobial therapy for pulmonary pathogenic colonisation and infection by Pseudomonas aeruginosa in cystic fibrosis patients. Clin Microbiol Infect 2005; 11: 690-703.

Jackson L, Waters V. Factors influencing the acquisition and eradication of early Pseudomonas aeruginosa infection in cystic fibrosis. J Cyst Fibros 2020; 20: 8-16.

Moreau-Marquis S, Bomberger JM, Anderson GG, et al. The DeltaF508-CFTR mutation results in increased biofilm formation by Pseudomonas aeruginosa by increasing iron availability. Am J Physiol Lung Cell Mol Physiol 2008; 295: L25-L37.

Yu S, Wei Q, Zhao T, et al. A survival strategy for Pseudomonas aeruginosa that uses exopolysaccharides to sequester and store iron to stimulate Psl-dependent biofilm formation. Appl Environ Microbiol 2016; 82: 6403-6413.

Billings N, Ramirez Millan M, Caldara M, et al. The extracellular matrix component Psl provides fast-acting antibiotic defense in Pseudomonas aeruginosa biofilms. PLoS Pathog 2013; 9: e1003526.

Ramphal R, Lhermitte M, Filliat M, et al. The binding of anti-pseudomonal antibiotics to macromolecules from cystic fibrosis sputum. J Antimicrob Chemother 1988; 22: 483-490.

Huang JX, Blaskovich MAT, Pelingon R, et al. Mucin binding reduces colistin antimicrobial activity. Antimicrob Agents Chemother 2015; 59: 5925-5931.

Butnarasu C, Barbero N, Pacheco D, et al. Mucin binding to therapeutic molecules: the case of antimicrobial agents used in cystic fibrosis. Int J Pharm 2019; 564: 136-144.

Russo P, Stigliani M, Prota L, et al. Gentamicin and leucine inhalable powder: what about antipseudomonal activity and permeation through cystic fibrosis mucus? Int J Pharm 2013; 440: 250-255.

Sun E, Gill EE, Falsafi R, et al. Broad-spectrum adaptive antibiotic resistance associated with Pseudomonas aeruginosa mucin-dependent surfing motility. Antimicrob Agents Chemother 2018; 62: e00848-18.

Landry RM, An D, Hupp JT, et al. Mucin-Pseudomonas aeruginosa interactions promote biofilm formation and antibiotic resistance. Mol Microbiol 2006; 59: 142-151.

Purdy Drew KR, Sanders LK, Culumber ZW, et al. Cationic amphiphiles increase activity of aminoglycoside antibiotic tobramycin in the presence of airway polyelectrolytes. J Am Chem Soc 2008; 131: 486-493.

Chiang WC, Nilsson M, Jensen PØ, et al. Extracellular DNA shields against aminoglycosides in Pseudomonas aeruginosa biofilms. Antimicrob Agents Chemother 2013; 57: 2352-2361.

Wilton M, Charron-Mazenod L, Moore R, et al. Extracellular DNA acidifies biofilms and induces aminoglycoside resistance in Pseudomonas aeruginosa. Antimicrob Agents Chemother 2016; 60: 544-553.

Mulcahy H, Charron-Mazenod L, Lewenza S. Extracellular DNA chelates cations and induces antibiotic resistance in Pseudomonas aeruginosa biofilms. PLoS Pathog 2008; 4: e1000213.

Broughton-Head VJ, Smith JR, Shur J, et al. Actin limits enhancement of nanoparticles diffusion through cystic fibrosis sputum by mucolytics. Pulm Pharmacol Ther 2007; 20: 708-717.

Line L, Alhede M, Kolpen M, et al. Physiological levels of nitrate support anoxic growth by denitrification of Pseudomonas aeruginosa at growth rates reported in cystic fibrosis lungs and sputum. Front Microbiol 2014; 5: 554.

Borriello G, Richards L, Ehrlich GD, et al. Arginine or nitrate enhances antibiotic susceptibility of Pseudomonas aeruginosa in biofilms. Antimicrob Agents Chemother 2006; 50: 382-384.

Zemke AC, Shiva S, Burn JL, et al. Nitrite modulates bacterial antibiotic susceptibility and biofilm formation in association with airway epithelial cells. Free Radic Biol Med 2014; 77: 307-316.

Kolpen M, Appeldorff CF, Brandt S, et al. Increased bactericidal activity of colistin on Pseudomonas aeruginosa biofilms in anaerobic conditions. Pathog Dis 2016; 74: ftv086.

Pamp SJ, Gjermansen M, Johansen HK, et al. Tolerance to the antimicrobial peptide colistin in Pseudomonas aeruginosa biofilms is linked to metabolically active cells, and depends on the pmr and mexAB-oprM genes. Mol Microbiol 2008; 68: 223-240.

Worlitzsch D, Tarran R, Ulrich $\mathrm{M}$, et al. Effects of reduced mucus oxygen concentration in airway Pseudomonas infections of cystic fibrosis patients. J Clin Invest 2002; 109: 317-325.

Yoon SS, Hennigan RF, Hilliard GM, et al. Pseudomonas aeruginosa anaerobic respiration in biofilms: relationships to cystic fibrosis pathogenesis. Dev Cell 2002; 3: 593-603. 
Bragonzi A, Worlitzsch D, Pier GB, et al. Nonmucoid Pseudomonas aeruginosa expresses alginate in the lungs of patients with cystic fibrosis and in a mouse model. $J$ Infect Dis 2005; 192: 410-419.

Borriello G, Werner E, Roe F, et al. Oxygen limitation contributes to antibiotic tolerance of Pseudomonas aeruginosa in biofilms. Antimicrob Agents Chemother 2004; 48: 2659-2664.

Hoffman LR, Richardson AR, Houston LS, et al. Nutrient availability as a mechanism for selection of antibiotic tolerant Pseudomonas aeruginosa within the CF airway. PLoS Pathog 2010; 6: e1000712.

Barth AL, Pitt TL. The high amino-acid content of sputum from cystic fibrosis patients promotes growth of auxotrophic Pseudomonas aeruginosa. J Med Microbiol 1996; 45: 110-119.

Thomas SR, Anjana R, Hodson ME, et al. Increased sputum amino acid concentrations and auxotrophy of Pseudomonas aeruginosa in severe cystic fibrosis lung disease. Thorax 2000; 55: 795-797.

Gill SK, Hui K, Farne H, et al. Increased airway glucose increases airway bacterial load in hyperglycaemia. Sci Rep 2016; 6: 27636.

She P, Wang Y, Liu Y, et al. Effects of exogenous glucose on Pseudomonas aeruginosa biofilm formation and antibiotic resistance. Microbiologyopen 2019; 8: e933.

Gordon CA, Hodges NA, Marriott C. Antibiotic interaction and diffusion through alginate and exopolysaccharide of cystic fibrosis-derived Pseudomonas aeruginosa. J Antimicrob Chemother 1988; 22: 667-674.

Tannenbaum CS, Hastie AT, Higgins ML, et al. Inability of purified Pseudomonas aeruginosa exopolysaccharide to bind selected antibiotics. Antimicrob Agents Chemother 1984; 25: 673-675.

Potter R, Hatley RHM. Effect of saline concentration on the minimum inhibitory concentration of colistimethate sodium and tobramycin. J Cyst Fibros 2010; 9: S42.

Yang Y, Tsifansky MD, Shin S, et al. Mannitol-guided delivery of ciprofloxacin in artificial cystic fibrosis mucus model. Biotechnol Bioeng 2011; 108: 1441-1449.

Lin Q, Pilewski JM, Di YP. Cystic fibrosis acidic microenvironment determines antibiotic susceptibility and biofilm formation of Pseudomonas aeruginosa. bioRxiv 2020; preprint [https://doi.org/10.1101/2020.10.15. 339978].

Strempe N, Neidig A, Nusser M, et al. Human host defense peptide LL-37 Stimulates virulence factor production and adaptive resistance in Pseudomonas aeruginosa. PLoS One 2013; 8: e82240.

Andrés MT, Viejo-Diaz M, Pérez F, et al. Antibiotic tolerance induced by lactoferrin in clinical Pseudomonas aeruginosa isolates from cystic fibrosis patients. Antimicrob Agents Chemother 2005; 49: 1613-1616.

Fujisawa T, Velichko S, Thai P, et al. Regulation of airway MUC5AC expression by IL-1b and IL-17A; the NF-kB paradigm. J Immunol 2009; 183: 6236-6243.

Riquelme SA, Liimatta K, Wong Fok Lung T, et al. Pseudomonas aeruginosa utilizes host-derived itaconate to redirect its metabolism to promote biofilm formation. Cell Metab 2020; 31: 1091-1106.e6.

Tan Q, Ai Q, Xu Q, et al. Polymorphonuclear leukocytes or hydrogen peroxide enhance biofilm development of mucoid Pseudomonas aeruginosa. Mediators Inflamm 2018; 2018: 8151362.

Yuan S, Hollinger M, Lachowicz-Scroggins ME, et al. Oxidation increases mucin polymer cross-links to stiffen airway mucus gels. Sci Transl Med 2015; 7: $276 \mathrm{ra27.}$

Fernandez-Petty CM, Hughes GW, Bowers HL, et al. A glycopolymer improves vascoelasticity and mucociliary transport of abnormal cystic fibrosis mucus. JCI Insight 2019; 4: e125954.

Ciofu O, Riis B, Pressler T, et al. Occurrence of hypermutable Pseudomonas aeruginosa in cystic fibrosis patients is associated with the oxidative stress caused by chronic lung inflammation. Antimicrob Agents Chemother 2005; 49: 2276-2282.

Mulcahy LR, Burns JL, Lory S, et al. Emergence of Pseudomonas aeruginosa strains producing high levels of persister cells in patients with cystic fibrosis. J Bacteriol 2010; 192: 6191-6199.

Pan X, Dong Y, Fan Z, et al. In vivo host environment alters Pseudomonas aeruginosa susceptibility to aminoglycoside antibiotics. Front Cell Infect Microbiol 2017; 7: 83.

Stites SW, Walters B, O'Brien-Ladner AR, et al. Increased iron and ferritin content of sputum from patients with cystic fibrosis or chronic bronchitis. Chest 1998; 114: 814-819.

Chillappagari S, Venkatesan S, Garapati V, et al. Impaired TLR4 and HIF expression in cystic fibrosis bronchial epithelial cells downregulates hemeoxygenase-1 and alters iron homeostasis in vitro. Am J Physiol Lung Cell Mol Physiol 2014; 307: L791-L799.

Reid DW, Lam QT, Schneider H, et al. Airway iron and iron-regulatory cytokines in cystic fibrosis. Eur Respir J 2004; 24: 286-291.

Kang D, Kirienkoa DR, Webster P, et al. Pyoverdine, a siderophore from Pseudomonas aeruginosa, translocates into $C$. elegans, removes iron, and activates a distinct host response. Virulence 2018; 9: 804-817.

Cigana C, Melotti P, Baldan R, et al. Genotypic and phenotypic relatedness of Pseudomonas aeruginosa isolates among the major cystic fibrosis patient cohort in Italy. BMC Microbiol 2016; 16: 142.

Hunter RC, Asfour F, Dingemans J, et al. Ferrous iron is a significant component of bioavailable iron in cystic fibrosis airways. mBio 2013; 4: e00557-13. 
Kang D, Kirienko NV. Interdependence between iron acquisition and biofilm formation in Pseudomonas aeruginosa. J Microbiol 2018; 56: 449-457.

O'May CY, Sanderson K, Roddam LF, et al. Iron-binding compounds impair Pseudomonas aeruginosa biofilm formation, especially under anaerobic conditions. J Med Microbiol 2009; 58: 765-773.

Wiens JR, Vasil Al, Schurr MJ, et al. Iron-regulated expression of alginate production, mucoid phenotype, and biofilm formation by Pseudomonas aeruginosa. mBio 2014; 5: e01010-13.

Tseng BS, Zhang W, Harrison JJ, et al. The extracellular matrix protects Pseudomonas aeruginosa biofilms by limiting the penetration of tobramycin. Environ Microbiol 2013; 15: 2865-2878.

enderson AG, Ehre C, Button B, et al. Cystic fibrosis airway secretions exhibit mucin hyperconcentration and increased osmotic pressure. J Clin Invest 2014; 124: 3047-3060.

Ehre C, Ridley C, Thornton DJ. Cystic fibrosis: an inherited disease affecting mucus producing organs. Int $J$ Biochem Cell Biol 2015; 52: 136-145.

Shak S, Capon DJ, Hellmiss R, et al. Recombinant human DNase I reduces the viscosity of cystic fibrosis sputum. Proc Natl Acad Sci USA 1990; 87: 9188-9192.

Ibáñez de Aldecoa AL, Zafra O, González-Pastor JE. Mechanisms and regulation of extracellular DNA release and its biological roles in microbial communities. Front Microbiol 2017; 8: 1390.

Vitse J, Devreese B. The contribution of membrane vesicles to bacterial pathogenicity in cystic fibrosis infections and healthcare associated pneumonia. Front Microbiol 2020; 11: 630.

Webb JS, Thompson LS, James S, et al. Cell death in Pseudomonas aeruginosa biofilm development. J Bacteriol 2003; 185: 4585-4592.

Alhede $\mathrm{M}$, Bjarnsholt $\mathrm{T}$, Jensen $\mathrm{P} \varnothing$, et al. Pseudomonas aeruginosa recognizes and responds aggressively to the presence of polymorphonuclear leukocytes. Microbiology 2009; 155: 3500-3508.

Dwyer M, Shan Q, D'Ortona S, et al. Cystic fibrosis sputum DNA has NETosis characteristics and neutrophil extracellular trap release is regulated by macrophage migration-inhibitory factor. J Innate Immun 2014; 6: 765-779.

Weiner OD, Servant G, Welch MD, et al. Spatial control of actin polymerization during neutrophil chemotaxis. Nat Cell Biol 2010; 1: 75-81.

Sheils CA, Kas J, Travassos W, et al. Actin filaments mediate DNA fiber formation in chronic inflammatory airway disease. Am J Pathol 1996; 148: 919-927.

Li LD, Crouzier T, Sarkar A, et al. Spatial configuration and composition of charge modulates transport into a mucin hydrogel barrier. Biophys J 2013; 105: 1357-1365.

König J, Schreiber R, Voelcker T, et al. The cystic fibrosis transmembrane conductance regulator (CFTR) inhibits ENaC through an increase in the intracellular $\mathrm{Cl}^{-}$concentration. EMBO Rep 2001; 2: 1047-1051.

Wauven C V, Pierard A, Kley-Raymann M, et al. Pseudomonas aeruginosa mutants affected in anaerobic growth on arginine: evidence for a four-gene cluster encoding the arginine deiminase pathway. $J$ Bacteriol 1984; 160: 918-934.

Jones KL, Hegab AH, Hillman BC, et al. Elevation of nitrotyrosine and nitrate concentrations in cystic fibrosis sputum. Pediatr Pulmonol 2000; 30: 79-85.

Grandjean Lapierre S, Phelippeau M, Hakimi C, et al. Cystic fibrosis respiratory tract salt concentration: an exploratory cohort study. Medicine 2017; 96: e8423.

King P, Citron DM, Griffith DC, et al. Effect of oxygen limitation on the in vitro activity of levofloxacin and other antibiotics administered by the aerosol route against Pseudomonas aeruginosa from cystic fibrosis patients. Diagn Microbiol Infect Dis 2010; 66: 181-186.

Gupta S, Laskar N, Kadouri DE. Evaluating the effect of oxygen concentrations on antibiotic sensitivity, growth, and biofilm formation of human pathogens. Microbiol Insights 2016; 9: 37-46.

Davey P, Barza M, Stuart M. Tolerance of Pseudomonas aeruginosa to killing by ciprofloxacin, gentamicin and imipenem in vitro and in vivo. J Antimicrob Chemother 1988; 21: 395-404.

Schaible B, Taylor CT, Schaffer K. Hypoxia increases antibiotic resistance in Pseudomonas aeruginosa through altering the composition of multidrug efflux pumps. Antimicrob Agents Chemother 2012; 56: 2114-2118.

3 Pompilio A, Crocetta V, Pomponio S, et al. In vitro activity of colistin against biofilm by Pseudomonas aeruginosa significantly improved under "cystic fibrosis-like" physochemical conditions. Diagn Microbiol Infect Dis 2015; 82: 318-325.

Hill D, Rose B, Pajkos A, et al. Antibiotic susceptibilities of Pseudomonas aeruginosa isolates derived from patients with cystic fibrosis under aerobic, anaerobic, and biofilm conditions. J Clin Microbiol 2005; 43: 5085-5090. Wetmore DR, Joseloff E, Pilewski J, et al. Metabolomic profiling reveals biochemical pathways and biomarkers associated with pathogenesis in cystic fibrosis cells. J Biol Chem 2010; 285: 30516-30522.

Quinn RA, Adem S, Mills RH, et al. Neutrophilic proteolysis in the cystic fibrosis lung correlates with a pathogenic microbiome. Microbiome 2019; 7: 23.

Sriramulu DD. Amino acids enhance adaptive behaviour of Pseudomonas aeruginosa in the cystic fibrosis lung environment. Microbiol Insights 2010; 3: MBI.S4694. 
98 Zabner J, Smith JJ, Karp PH, et al. Loss of CFTR chloride channels alters salt absorption by cystic fibrosis airway epithelia in vitro. Mol Cell 1998; 2: 397-403.

99 Simonin J, Bille E, Crambert G, et al. Airway surface liquid acidification initiates host defense abnormalities in cystic fibrosis. Sci Rep 2019; 9: 6516.

100 Tate S, MacGregor G, Davis M, et al. Airways in cystic fibrosis are acidified: detection by exhaled breath condensate. Thorax 2002; 57: 926-929.

101 Abou Alaiwa MH, Reznikov LR, Gansemer ND, et al. pH modulates the activity and synergism of the airway surface liquid antimicrobials $\beta$-defensin-3 and LL-37. Proc Natl Acad Sci USA 2014; 111: 18703-18708.

102 Bonfield T, Chmiel JF. Impaired innate immune cells in cystic fibrosis: is it really a surprise? J Cyst Fibros 2017; 16: 433-435.

103 Dürr UHN, Sudheendra US, Ramamoorthy A. LL-37, the only human member of the cathelicidin family of antimicrobial peptides. Biochim Biophys Acta 2006; 1758: 1408-1425.

104 Overhage J, Campisano A, Bains M, et al. Human host defense peptide LL-37 prevents bacterial biofilm formation. Infect Immun 2008; 76: 4176-4182.

105 Singh PK. Iron sequestration by human lactoferrin stimulates $P$. aeruginosa surface motility and blocks biofilm formation. BioMetals 2004; 17: 267-270.

106 Cutone A, Lepanto MS, Rosa L, et al. Aerosolized bovine lactoferrin counteracts infection, inflammation and iron dysbalance in a cystic fibrosis mouse model of Pseudomonas aeruginosa chronic lung infection. Int $J$ Mol Sci 2019; 20: 2128.

107 Chen Y, Thai P, Zhao YH, et al. Stimulation of airway mucin gene expression by interleukin (IL)-17 through IL-6 paracrine/autocrine loop. J Biol Chem 2003; 278: 17036-17043.

108 Groneberg DA, Eynott PR, Oates T, et al. Expression of MUC5AC and MUC5B mucins in normal and cystic fibrosis lung. Respir Med 2002; 96: 81-86.

109 Dittrich AS, Kühbandner I, Gehrig S, et al. Elastase activity on sputum neutrophils correlates with severity of lung disease in cystic fibrosis. Eur Respir J 2018; 51: 1701910.

110 Shao MXG, Nadel JA. Neutrophil elastase induces MUC5AC mucin production in human airway epithelial cells via a cascade involving protein kinase $C$, reactive oxygen species, and TNF- $\alpha$-converting enzyme. J Immunol 2005; 175: 4009-4016.

111 Riquelme SA, Lozano C, Moustafa AM, et al. CFTR-PTEN-dependent mitochondrial metabolic dysfunction promotes Pseudomonas aeruginosa airway infection. Sci Transl Med 2019; 11: eaav4634.

112 Crabbé A, Ostyn L, Staelens S, et al. Host metabolites stimulate the bacterial proton motive force to enhance the activity of aminoglycoside antibiotics. PLoS Pathog 2019; 15: e1007697.

113 Meylan S, Porter CBM, Yang JH, et al. Carbon sources tune antibiotic susceptibility in Pseudomonas aeruginosa via tricarboxylic acid cycle control. Cell Chem Biol 2017; 24: 195-206.

114 Amulic B, Cazalet C, Hayes GL, et al. Neutrophil function: from mechanisms to disease. Annu Rev Immunol 2012; 30: 459-489.

115 Roum JH, Buhl R, McElvaney NG, et al. Systemic deficiency of glutathione in cystic fibrosis. J Appl Physiol 1993; 75: 2419-2424.

116 Macía MD, Blanquer D, Togores B, et al. Hypermutation is a key factor in development of multiple-antimicrobial resistance in Pseudomonas aeruginosa strains causing chronic lung infections. Antimicrob Agents Chemother 2005; 49: 3382-3386.

117 Grassi L, Di Luca M, Maisetta G, et al. Generation of persister cells of Pseudomonas aeruginosa and Staphylococcus aureus by chemical treatment and evaluation of their susceptibility to membrane-targeting agents. Front Microbiol 2017; 8: 1917.

118 Sindeldecker D, Moore K, Li A, et al. Novel aminoglycoside-tolerant phoenix colony variants of Pseudomonas aeruginosa. Antimicrob Agents Chemother 2020; 64: e00623-20.

119 Kramer R, Sauer-Heilborn A, Welte T, et al. Cohort study of airway mycobiome in adult cystic fibrosis patients: differences in community structure between fungi and bacteria reveal predominance of transient fungal elements. J Clin Microbiol 2015; 53: 2900-2907.

120 Willger SD, Grim SL, Dolben EL, et al. Characterization and quantification of the fungal microbiome in serial samples from individuals with cystic fibrosis. Microbiome 2014; 2: 40.

121 Acosta N, Whelan FJ, Somayaji R, et al. The evolving cystic fibrosis microbiome: a comparative cohort study spanning 16 years. Ann Am Thorac Soc 2017; 14: 1288-1297.

122 Coburn B, Wang PW, Diaz Caballero J, et al. Lung microbiota across age and disease stage in cystic fibrosis. Sci Rep 2015; 5: 10241.

123 Vandeplassche E, Tavernier S, Coenye T, et al. Influence of the lung microbiome on antibiotic susceptibility of cystic fibrosis pathogens. Eur Respir Rev 2019; 28: 190041.

124 Magalhães AP, Lopes SP, Pereira MO. Insights into cystic fibrosis polymicrobial consortia: the role of species interactions in biofilm development, phenotype, and response to in-use antibiotics. Front Microbiol 2017; 7: 2146. 
125 Bragonzi A, Farulla I, Paroni M, et al. Modelling co-infection of the cystic fibrosis lung by Pseudomonas aeruginosa and Burkholderia cenocepacia reveals influences on biofilm formation and host response. PLoS One 2012; 7: e52330.

126 Waite RD, Qureshi MR, Whiley RA. Modulation of behaviour and virulence of a high alginate expressing Pseudomonas aeruginosa strain from cystic fibrosis by oral commensal bacterium Streptococcus anginosus. PLoS One 2017; 12: e0173741.

127 Tognon M, Köhler T, Gdaniec BG, et al. Co-evolution with Staphylococcus aureus leads to lipopolysaccharide alterations in Pseudomonas aeruginosa. ISME J 2017; 11: 2233-2243.

128 Alvarez-Ortega C, Wiegand I, Olivares J, et al. Genetic determinants involved in the susceptibility of Pseudomonas aeruginosa to $\beta$-lactam antibiotics. Antimicrob Agents Chemother 2010; 54: 4159-4167.

129 Rogers GB, Carroll MP, Serisier DJ, et al. Characterization of bacterial community diversity in cystic fibrosis lung infections by use of $16 \mathrm{~S}$ ribosomal DNA terminal restriction fragment length polymorphism profiling. J Clin Microbiol 2004; 42: 5176-5183.

130 Vandeplassche E, Sass A, Lemarcq A, et al. In vitro evolution of Pseudomonas aeruginosa AA2 biofilms in the presence of cystic fibrosis lung microbiome members. Sci Rep 2019; 9: 12859.

131 Muhlebach MS, Hatch JE, Einarsson GG, et al. Anaerobic bacteria cultured from cystic fibrosis airways correlate to milder disease: a multisite study. Eur Respir J 2018; 52: 1800242.

132 Sherrard LJ, McGrath S, Mcllreavey L, et al. Production of extended-spectrum $\beta$-lactamases and the potential indirect pathogenic role of Prevotella isolates from the cystic fibrosis respiratory microbiota. Int $J$ Antimicrob Agents 2016; 47: 140-145.

133 Trejo-Hernández A, Andrade-Domínguez A, Hernández M, et al. Interspecies competition triggers virulence and mutability in Candida albicans-Pseudomonas aeruginosa mixed biofilms. ISME J 2014; 8: 1974-1988.

134 Wat D, Gelder C, Hibbitts S, et al. The role of respiratory viruses in cystic fibrosis. J Cyst Fibros 2008; 7: 320-328.

135 Hendricks MR, Lashua LP, Fischer DK, et al. Respiratory syncytial virus infection enhances Pseudomonas aeruginosa biofilm growth through dysregulation of nutritional immunity. Proc Natl Acad Sci USA 2016; 113: 1642-1647.

136 Hendricks MR, Lane S, Melvin JA, et al. Extracellular vesicles promote transkingdom nutrient transfer during viral-bacterial co-infection. Cell Rep 2021; 34: 108672.

137 Palmer KL, Aye LM, Whiteley M. Nutritional cues control Pseudomonas aeruginosa multicellular behavior in cystic fibrosis sputum. J Bacteriol 2007; 189: 8079-8087.

138 Quinn RA, Comstock W, Zhang T, et al. Niche partitioning of a pathogenic microbiome driven by chemical gradients. Sci Adv 2018; 4: eaau1908.

139 Quinn RA, Lim YW, Maughan H, et al. Biogeochemical forces shape the composition and physiology of polymicrobial communities in the cystic fibrosis lung. mBio 2014; 5: e00956-13.

140 Davis SD, Fordham LA, Brody AS, et al. Computed tomography reflects lower airway inflammation and tracks changes in early cystic fibrosis. Am J Respir Crit Care Med 2007; 175: 943-950.

141 Garg N, Wang M, Hyde E, et al. Three-dimensional microbiome and metabolome cartography of a diseased human lung. Cell Host Microbe 2017; 22: 705-716.e4.

142 Zhou-Suckow Z, Duerr J, Hagner M, et al. Airway mucus, inflammation and remodeling: emerging links in the pathogenesis of chronic lung diseases. Cell Tissue Res 2017; 367: 537-550.

143 Winstanley C, O'Brien S, Brockhurst MA. Pseudomonas aeruginosa evolutionary adaptation and diversification in cystic fibrosis chronic lung infections. Trends Microbiol 2016; 24: 327-337.

144 Sousa AM, Monteiro R, Pereira MO. Unveiling the early events of Pseudomonas aeruginosa adaptation in cystic fibrosis airway environment using a long-term in vitro maintenance. Int J Med Microbiol 2018; 308: 1053-1064.

145 Bianconi I, D'Arcangelo S, Esposito A, et al. Persistence and microevolution of Pseudomonas aeruginosa in the cystic fibrosis lung: a single-patient longitudinal genomic study. Front Microbiol 2019; 9: 3242.

146 Markussen T, Marvig RL, Gomez-Lozano M, et al. Environmental heterogeneity drives within-host diversification and evolution of Pseudomonas aeruginosa. mBio 2014; 5: e01592-14.

147 Schick A, Kassen R. Rapid diversification of Pseudomonas aeruginosa in cystic fibrosis lung-like conditions. Proc Natl Acad Sci USA 2018; 115: 10714-10719.

148 Darch SE, McNally A, Harrison F, et al. Recombination is a key driver of genomic and phenotypic diversity in a Pseudomonas aeruginosa population during cystic fibrosis infection. Sci Rep 2015; 5: 7649.

149 Smith EE, Buckley DG, Wu Z, et al. Genetic adaptation by Pseudomonas aeruginosa to the airways of cystic fibrosis patients. Proc Natl Acad Sci USA 2006; 103: 8487-8492.

150 Pestrak MJ, Chaney SB, Eggleston HC, et al. Pseudomonas aeruginosa rugose small-colony variants evade host clearance, are hyper-inflammatory, and persist in multiple host environments. PLoS Pathog 2018; 14: e1006842.

151 Malhotra S, Hayes D, Wozniak DJ. Mucoid Pseudomonas aeruginosa and regional inflammation in the cystic fibrosis lung. J Cyst Fibros 2019; 18: 796-803. 
152 Rees VE, Deveson Lucas DS, López-Causapé C, et al. Characterization of hypermutator Pseudomonas aeruginosa isolates from patients with cystic fibrosis in Australia. Antimicrob Agents Chemother 2019; 63: e02538-18.

153 Cruz RL, Asfahl KL, Van den Bossche S, et al. RhlR-regulated acyl-homoserine lactone quorum sensing in a cystic fibrosis isolate of Pseudomonas aeruginosa. mBio 2020; 11: e00532-20.

154 Toska J, Sun Y, Carbonell DA, et al. Diversity of virulence phenotypes among type III secretion negative Pseudomonas aeruginosa clinical isolates. PLoS One 2014; 9: e86829.

155 Rodríguez-Rojas A, Mena A, Martín S, et al. Inactivation of the hmgA gene of Pseudomonas aeruginosa leads to pyomelanin hyperproduction, stress resistance and increased persistence in chronic lung infection. Microbiology 2009; 155: 1050-1057.

156 Malhotra S, Limoli DH, English AE, et al. Mixed communities of mucoid and nonmucoid Pseudomonas aeruginosa exhibit enhanced resistance to host antimicrobials. mBio 2018; 9: e00275-18.

157 Kidd TJ, Canton R, Ekkelenkamp M, et al. Defining antimicrobial resistance in cystic fibrosis. J Cyst Fibros 2018; 17: 696-704.

158 Clark ST, Caballero JD, Cheang M, et al. Phenotypic diversity within a Pseudomonas aeruginosa population infecting an adult with cystic fibrosis. Sci Rep 2015; 5: 10932.

159 Ranganathan SC, Skoric B, Ramsay KA, et al. Geographical differences in first acquisition of Pseudomonas aeruginosa in cystic fibrosis. Ann Am Thorac Soc 2013; 10: 108-114.

160 Skov M, Hansen CR, Pressler T. Cystic fibrosis - an example of personalized and precision medicine. APMIS 2019; 127: 352-360.

161 De Boeck K, Zolin A, Cuppens H, et al. The relative frequency of CFTR mutation classes in European patients with cystic fibrosis. J Cyst Fibros 2014; 13: 403-409.

162 Horsley A, Siddiqui S. Putting lung function and physiology into perspective: cystic fibrosis in adults. Respirology 2015; 20: 33-45.

163 Bonadia LC, de Lima Marson FA, Ribeiro JD, et al. CFTR genotype and clinical outcomes of adult patients carried as cystic fibrosis disease. Gene 2014; 540: 183-190.

164 Yi B, Dalpke AH, Boutin S. Changes in the cystic fibrosis airway microbiome in response to CFTR modulator therapy. Front Cell Infect Microbiol 2021; 11: 548613.

165 Schneider EK, Azad MAK, Han M-L, et al. An "unlikely" pair: the antimicrobial synergy of polymyxin B in combination with the cystic fibrosis trans-membrane conductance regulator drugs KALYDECO and ORKAMBI. ACS Infect Dis 2017; 176: 139-148.

166 Elborn JS. Cystic fibrosis. Lancet 2016; 388: 2519-2531.

167 Moran A, Becker D, Casella SJ, et al. Epidemiology, pathophysiology, and prognostic implications of cystic fibrosis-related diabetes: a technical review. Diabetes Care 2010; 33: 2677-2683.

168 Bevivino A, Bacci G, Taccetti G, et al. WS19-4. The personalised temporal dynamics of microbiome in the airways of cystic fibrosis patients. J Cyst Fibros 2019; 18: S36.

169 Raghuvanshi R, Vasco K, Vázquez-Baeza Y, et al. High-resolution longitudinal dynamics of the cystic fibrosis sputum microbiome and metabolome through antibiotic therapy. mSystems 2020; 5: e00292-20.

170 De Sutter P-J, Gasthuys E, Van Braeckel E, et al. Pharmacokinetics in patients with cystic fibrosis: a systematic review of data published between 1999 and 2019. Clin Pharmacokinet 2020; 59: 1551-1573.

171 Bos AC, Passé KM, Mouton JW, et al. The fate of inhaled antibiotics after deposition in cystic fibrosis: how to get drug to the bug? J Cyst Fibros 2017; 16: 13-23.

172 Romàn CM, Loughlin HC, Aliaj E, et al. Hemoptysis from the perspective of people with cystic fibrosis. Clin Respir J 2020; 14: 299-303.

173 Crabbé A, Liu Y, Matthijs N, et al. Antimicrobial efficacy against Pseudomonas aeruginosa biofilm formation in a three-dimensional lung epithelial model and the influence of fetal bovine serum. Sci Rep 2017; 7: 43321.

174 Vandeplassche E, Sass A, Ostyn L, et al. Antibiotic susceptibility of cystic fibrosis lung microbiome members in a multispecies biofilm. Biofilm 2020; 2: 100031.

175 Smith S, Waters V, Jahnke N, et al. Standard versus biofilm antimicrobial susceptibility testing to guide antibiotic therapy in cystic fibrosis. Cochrane Database Syst Rev 2020; 6: CD009528. 